\title{
Intraoperative Fraction of Inspired Oxygen: An Enigma to be
}

\section{Unravelled}

\section{Agrawal J* and Rajput A}

Gajra Raja Medical College Gwalior, India

*Corresponding author: Jitendra Agrawal, Associate Professor, Gajra Raja Medical

College Gwalior, (MP) India, Tel: 9300009942; Email: drjagrawal@gmail.com

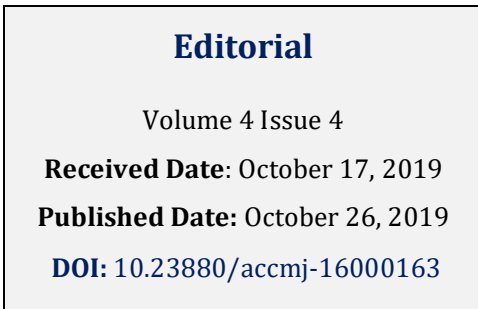

\section{Editorial}

To date, plethora of randomized controlled trials have been done to find out clinical impact of fraction of inspired oxygen $\left(\mathrm{FiO}_{2}\right)$ used in perioperative period. The oxygen has been in use in providing anaesthesia since ages. In current day practice, oxygen's use has become an integral part of giving safe anaesthesia. Let alone general anaesthesia (GA), oxygen is almost invariably used even in regional anaesthesia and procedural sedation and analgesia (PSA) in varying concentrations depending upon various factors like depth of sedation, age, respiratory depression and patient's condition etc. The ideal $\mathrm{FiO}_{2}$, that it should be used at, is still dubious. However, many of us use oxygen, dogmatically in perioperative period, which is affected by one's clinical experience, training and local practice, etc.

Previously, there was a misbelief that oxygen administration, even at higher concentrations, affects the clinical outcome positively. In past few decades, as we have grown in our comprehension about deleterious effects of oxygen, its concentration $\left(\mathrm{FiO}_{2}\right)$ and roll per se is being overwhelmingly challenged.

As of now, it has been tried to weigh the benefits versus risks of oxygen use by systemic reviews and metaanalyses, yet ambiguity prevails due to dearth of outright conclusions and evidence based guidelines. In the current review, a critical appraisal is attempted to analyse advantages and disadvantages of different oxygen concentration, taking dual nature into consideration through a literature search in medical database i.e. PubMed, Web of science, google scholar.

Intraoperative Fraction of Inspired Oxygen: An Enigma to be Unravelled
Recently, WHO released recommendations, pertaining perioperative use of oxygen as to reduce the incidence of surgical site infections (SSIs), based on a meta-analysis of RCTs and unanimity among experts [1]. The WHO upheld the use of $\mathrm{FiO}_{2}$ of 0.8 in intubated patients and for few hours after surgery, which drew widespread flak from anaesthesiologists and researchers [2,3].

Oxygen has been in use as a carrier gas for inhalational anaesthetics since the inception of nitrous oxide and ether in anaesthesia practice [4]. In the beginning, $\mathrm{O}_{2}$ was used at room air concentration but with advent and introduction of contemporary equipments, higher fractions of $\mathrm{O}_{2}$, were started being taken into consideration. At the time of induction, preoxygenation with $100 \% \mathrm{O}_{2}$, to increase the time for airway instrumentation has become a routine practice, which is subsequently followed by $\mathrm{FiO}_{2}$ of 0.4-0.5 while maintenance [5]. This is not only constrained to difficult airways, since hypoxia is one of the most dreaded and formidable event that anaesthesiologists come across. Despite being heavier and denser than nitrogen, oxygen, even at these high concentrations does not affect airflow dynamics significantly [6].

The scepticism about appropriate $\mathrm{FiO}_{2}$ in perioperative period has escalated ever since the dual nature of $\mathrm{O} 2$ has come to the light. Radical oxygen metabolites (ROMs), produced by incomplete reduction of $\mathrm{O}_{2}$, cause structural damage to DNA, epithelium, endothelium and eventually ending up with organ damage like brain, lungs etc $[7,8]$. However, a number of factors affect the clinical end result like: concentration, 


\section{Anaesthesia \& Critical Care Medicine Journal}

duration of use and age etc. [7] among aforementioned factors, age is an important one, as individuals of extreme age are very sensitive to the detrimental effects of high $\mathrm{O}_{2}$ concentrations.

The dictum that endorses higher $\mathrm{FiO}_{2}$ in perioperative period is the roll of ROMs in immune system. Superoxide and hydrogen peroxide have a pivotal role in defence against bacterial activity by combining with chloride to form hypochlorous acid, and by inciting gene expression of proinflammatory cytokines $[9,10]$. Therefore, by supplementing oxygen at higher concentration, cellular immunity may be strengthened specially in context of general anaesthesia (GA) as GA is believed to have an alleviating effect on the immunity [10-12].

Hyperoxia affects the pulmonary and systemic vascular resistance greatly. With high oxygen tension, pulmonary vascular resistance decreases, while systemic resistance rises. This results in preferential regional redistribution of blood flow to lungs [13]. This redistribution has ameliorating effect on high ventilationperfusion $(\mathrm{V} / \mathrm{Q})$ mismatch, since it increases total available surface area for gaseous exchange [14]. Nonetheless, high $\mathrm{FiO}_{2}$ is seldom recommended, as it mitigates systemic blood flow (cerebral and coronary blood flow are of utmost importance) due to rise in systemic vascular resistance and therefore oxygen's availability in smaller capillaries is lowered [15]. As oxygen is mainly transported by haemoglobin, which already remains fully saturated at normal inspired $\mathrm{O}_{2}$ fraction; high $\mathrm{FiO}_{2}$ increases $\mathrm{O}_{2}$ content of blood inconsequentially [16]. Thereby, high $\mathrm{FiO}_{2}$ increases the potential risk of tissue hypoxia due to reduced capillary perfusion and advantage in prevention of SSIs by producing of ROMs also goes off.

Ventilatory heterogeneity is inevitable in anaesthesia due factors like: mechanical ventilation, position during surgery, pain, muscle relaxation, respiratory depression etc $[17,18]$. When oxygen is used at higher concentration, it promotes repeated alveolar collapse called absorption atelectasis. When used in high concentration, $\mathrm{O}_{2}$ rapidly replaces nitrogen from lungs and a very high pressure gradient develops between alveoli and pulmonary capillaries, which facilitates rapid diffusion of $\mathrm{O}_{2}$ across diffusion surface to capillaries, resulting in cyclical collapse of alveoli $[19,20] . \mathrm{FiO}_{2}$ of 0.8 is generally considered threshold for this and sometimes atelectasis may not even respond to recruitment manoeuvres [2123].
Use of high $\mathrm{FiO}_{2}$ in neonate and infants, may have severe repercussions as their organs, especially brain and lungs are very sensitive for getting affected adversely by ROMs. Broncho-pulmonary dysplasia, bronchial hyper reactivity, retinopathy of prematurity, pulmonary hypertension and fibrosis are few common and devastating consequences [24,25]. Moreover, unloading of oxygen from fetal haemoglobin is affected adversely, which is attributed to higher affinity of fetal haemoglobin for oxygen, therefore despite having higher oxygen content in blood, tissue hypoxia may ensue [26]. Oxygen therapy is critical in congenital heart diseases like acyanotic heart diseases, where preferential regional redistribution of blood to lungs increases shunt fraction and lowers cardiac output and systemic perfusion [27]. As infants are not privileged with a decent functional residual capacity, which is ascribed to anatomical characteristics of their respiratory system (chest wall is more compliant and lungs have higher elastic recoil), they are prone for hypoxia while managing airway. Henceforth, preoxygenation with $100 \%$ oxygen is advocated in routine practice [28]. However, this practice facilitates alveolar collapse as per the mechanism of absorption atelectasis.

Nowadays, the prevalence of chronic obstructive pulmonary disease (COPD) has rise due to progressive changes in environment and lifestyle. Use of oxygen is crucial and challenging in patients because of potential of oxidative stress [28]. Moreover, $\mathrm{CO}_{2}$ has a pivotal role in maintaining respiratory drive so patient may hypo ventilate when higher $\mathrm{FiO}_{2}$ is used in perioperative periods.

\section{Conclusion}

The rationale behind using oxygen in perioperative period is to maintain adequate tissue oxygenation and to parry catastrophes during airway handling. Because of dual nature of this gas, it's often considered a double edged sword as hypoxia is one of the most feared nightmares, while on the other extreme; hyperoxia virtually affects almost every organ system detrimentally. Therefore, one should be conversant about consequences or repercussions when using oxygen. The ideal perioperative $\mathrm{O}_{2}$ concentration is still a matter of debate and while determining the same, age specific aspects of oxygen demand and toxicity should be taken into consideration. A higher FiO2, not more than $80 \%$, may be used in challenging situations like airway instrumentation or while recovering from anaesthesia, while $30-35 \%$ is considered adequate in maintenance of anaesthesia. 


\section{Anaesthesia \& Critical Care Medicine Journal}

WHO's recommendation of use of higher FiO2 $(>0.8)$, could not be validated and they eventually decided to change it from strong to moderate recommendation. Since conspicuous conclusions have not been reached at, and data remained contentious, more comprehensive researches are to be undertaken to figure out beneficial and harmful effects of perioperative use of oxygen at different concentrations.

\section{References}

1. Allegranzi B, Zayed B, Bischoff P, Kubilay NZ, de Jonge $S$, et al. (2016) New WHO recommendations on intraoperative and postoperative measures for surgical site infection prevention: an evidence-based global perspective. Lancet Infect Dis 16(12): 288-303.

2. Hedenstierna G, Perchiazzi G, Meyhoff CS, Larsson A (2017) Who can make sense of the WHO guidelines to prevent surgical site infection? Anesthesiology 126(5): 771-773.

3. Myles PS, Kurz A (2017) Supplemental oxygen and surgical site infection: getting to the truth. BrJAnaesth 119(1): 13-16.

4. HeffnerJE (2013) The story of oxygen. Respir Care 58(1): 18-31.

5. Benumof JL (1999) Preoxygenation: best method for both efficacy and efficiency. Anesthesiology 91(3): 603-605.

6. Habre W, Asztalos T, Sly PD, Petak F (2001) Viscosity and density of common anaesthetic gases: implications for flow measurements. $\mathrm{Br} \mathrm{J}$ Anaesth 87(4): 602-607.

7. Auten RL, Davis JM 2009) Oxygen toxicity and reactive oxygen species: the devil is in the details. Pediatr Res 66(2): 121-127.

8. Andreoli TE (2000) Free radicals and oxidative stress. Am J Med 108(8): 650-651.

9. Furtmuller PG, Burner U, Obinger C (1998) Reaction of myeloperoxidase compound I with chloride, bromide, iodide, and thiocyanate. Biochemistry 37(51): 17923-17930.

10. KotaniN, Hashimoto H, Sessler DI, Muraoka M, Hashiba E, et al. (2000) Supplemental intraoperative oxygen augments antimicrobial and proinflammatory

Agrawal J and Rajput A. Intraoperative Fraction of Inspired Oxygen: An Enigma to be Unravelled. Anaesth Critic Care Med J 2019, 4(4): 000163. responses of alveolar macrophages. Anesthesiology 93(1): 15-25.

11. Kotani N, Lin CY, Wang JS, Gurley JM, Tolin FP, et al. (1995) Loss of alveolar macrophages during anesthesia and operation in humans. Anesth Analg 81(6): 1255-1262.

12. Kabon B, Kurz A (2006) Optimal perioperative oxygen administration. Curr Opin Anaesthesiol 19(1): 11-18.

13. Ley S, Puderbach M, RisseF, Ley Zaporozhan J, Eichinger M, et al. (2007) Impact of oxygen inhalation on the pulmonary circulation: assessment by magnetic resonance (MR)-perfusion and MR-flow measurements. Invest Radiol 42(5): 283-290.

14. Lumb $A B$, Walton LJ (2012) Perioperative oxygen toxicity. Anesthesiol Clin 30(4): 591-605.

15. Niijima S, Shortland DB, Levene MI, Evans DH (1988) Transient hyperoxia and cerebral blood flow velocity in infants born prematurely and at full term. Arch Dis Child 63(10): 1126-1130.

16. Lumb AB (2010) Nunn's Applied Respiratory Physiology $8^{\text {th }} \quad$ (Edn.), New York: Churchill Livingstone.

17. Rothen HU, Sporre B, Engberg G, Wegenius G, Hedenstierna G (1998) Airway closure, atelectasis and gas exchange during general anaesthesia.Br J Anaesth 81(5): 681-686.

18. Hedenstierna G (2003) Alveolar collapse and closure of airways: regular effects of anaesthesia. Clin Physiol Funct Imaging 23(3): 123-129.

19. Lumb AB (2007) Just a little oxygen to breathe as you go off to sleep...is it always a good idea? Br 99(6): 769-771.

20. Dantzker DR, Wagner PD, West JB (1974) Proceedings: Instability of poorly ventilated lung units during oxygen breathing. J Physiol 242(2): 72.

21. Magnusson L, Spahn DR (2003) New concepts of atelectasis during general anaesthesia. Br JAnaesth 91(1): 61-72.

22. JoyceCJ, Williams AB (1999) Kinetics of absorption atelectasis during anesthesia: a mathematical model. J Appl Physiol 86(4): 1116-1125. 


\section{Anaesthesia \& Critical Care Medicine Journal}

23. Rothen HU, Sporre B, Engberg G, Wegenius G, Hogman M, et al. (1995) Influence of gas composition on recurrence of atelectasis after a reexpansion maneuver during general anesthesia. Anesthesiology 82(4): 832-842.

24. Kaplan E, Bar-Yishay E, Prais D, Klinger G, Mei-Zahav M, et al. (2012) Encouraging pulmonary outcome for surviving, neurologically intact, extremely premature infants in the post surfactant era. Chest 142(3): 725733.

25. Rowland R, Newman CG (1969) pulmonary complications of oxygen therapy. J Clin Pathol 22(2): 192-198.
26. Fouzas S, Priftis KN, Anthracopoulos MB (2011) Pulseoximetry in pediatric practice. Pediatrics 128(4): 740-752.

27. Beekman RH, Rocchini AP, Rosenthal A (1983) Cardiovascular effects of breathing 95 percent oxygen in children with congenital heart disease. Am J Cardiol 52(1): 106-111.

28. Hardman JG, Wills JS (2006) The development of hypoxaemia during apnoea in children: a computational modelling investigation. Br J Anaesth 97(4): 564-567. 